\title{
Clinical applications of PD- I-based therapy: a focus on pembrolizumab (MK-3475) in the management of melanoma and other tumor types
}

This article was published in the following Dove Press journal:

OncoTargets and Therapy

22 April 2015

Number of times this article has been viewed

\author{
Tara C Gangadhar' \\ April KS Salama ${ }^{2}$ \\ 'Division of Hematology/Oncology, \\ Department of Medicine, Abramson \\ Cancer Center of the University \\ of Pennsylvania, Philadelphia, \\ PA, USA; ${ }^{2}$ Division of Medical \\ Oncology, Department of Medicine, \\ Duke University Medical Center, \\ Durham, NC, USA
}

\begin{abstract}
Preclinical work has led to an increased understanding of the immunomodulatory mechanisms involved in the regulation of the antitumor response in a variety of tumor types. PD-1 (programmed death 1) appears to be a key checkpoint involved in immune suppression in the tumor microenvironment, even in diseases not previously thought to be sensitive to immune manipulation. More recently, the subsequent clinical development of PD-1-based therapy has resulted in a major breakthrough in the field of oncology. Pembrolizumab, a humanized highly selective IgG4 anti-PD-1 monoclonal antibody, was recently approved for the treatment of advanced melanoma based on promising early-phase clinical data. Encouraging results have also been seen in other malignancies, and PD-1-targeted therapies are likely to markedly change the treatment landscape. Future work will center on rationally designed combination strategies in order to potentiate the antitumor immune response and overcome mechanisms of resistance.

Keywords: PD-1, cancer, pembrolizumab, nivolumab, immunotherapy, antitumor activity
\end{abstract}

\section{Introduction}

Immune-directed therapies have recently demonstrated improved efficacy in several tumor types, with significant advances resulting from the development of PD-1 (programmed death 1)-blocking agents, including pembrolizumab (formerly MK-3475). Drugs with immune-mediated activity have been used for decades in oncology, with high-dose interleukin-2 (IL-2) having been approved for metastatic melanoma in 1998 and adjuvant interferon- $\alpha 2 \mathrm{~B}$ approved in 1995. ${ }^{1,2}$ More recently, the CTLA-4 blocking agent, ipilimumab, and the vaccine therapy sipuleucel-T have gained approvals as well; however, while a small number of patients do gain long-lasting clinical benefit with each of these agents, the overall survival benefit in all patients treated with these agents remains small and the potential toxicity is significant. ${ }^{3,4}$

The initial reports of clinical activity with PD-1 blockade using novel investigational agents demonstrated the feasibility of high rates of durable responses with immune therapy in several tumor types, in addition to melanoma and renal cell carcinoma (RCC), which had long been considered to be potentially immune responsive. The great potential for clinical activity with highly effective immune-directed therapy across many tumor types has now been realized; several ongoing and recently completed clinical trials have focused on developing safe and effective single-agent and combination immune therapy strategies, including PD-1 blockade. The newly realized possibilities of long-term disease control, improved survival, and, perhaps, even cure with effective immune-directed therapies highlight the importance of modulating the immune system in the care of oncology patients.
Correspondence: April KS Salama Division of Medical Oncology, Department of Medicine, Duke University Medical Center, I Trent Drive, Room 25।78, Morris Building, DUMC 3198, Durham, NC 277I0, USA

$\mathrm{Tel}+\mathrm{I} 9196816932$

Fax +19196845163

Email april.salama@duke.edu 
Here we review the clinical development of PD-1-based therapy, with a particular focus on the PD-1-blocking agent, pembrolizumab, in the treatment of advanced cancer.

\section{Mode of action and pharmacology of pembrolizumab}

The PD-1 pathway is an immune regulatory mechanism (Figure 1). The discovery of PD-1 blockade as a potential mechanism of T-cell activation and antitumor activity was originally based on studies of $\mathrm{T}$ cells in chronic infection models. Activated T cells (defined by the expression of activation markers $\mathrm{CD} 69^{\mathrm{hi}}, \mathrm{CD} 44^{\mathrm{hi}}$, and $\mathrm{CD} 62 \mathrm{~L}^{\mathrm{lo}}$ ) which were lacking effector function were initially described as key mediators underlying the mechanism of viral immune evasion. ${ }^{5}$ In the presence of chronic viral infection, CD8 $\mathrm{T}$ cells develop a dysfunctional or exhausted T-cell phenotype characterized by a higher expression of PD-1 compared to functional T cells. Functional T cells may transiently express negative regulatory molecules, including PD-1, in states of activation; however, persistently high expression indicates an exhausted and dysfunctional T-cell phenotype. ${ }^{6,7}$ Of note, blockade of the PD-1 and ligand (PD-L1) interaction in a mouse model of chronic infection could restore T-cell function, with a resulting reduction in viral load. ${ }^{8}$ Subsequent studies identified the same pattern of provoked T-cell dysfunction as a mechanism of tumor evasion of the immune system, leading to the development of therapeutic PD-1 blockade in patients with advanced malignancies. ${ }^{9-12}$

Pembrolizumab is a humanized PD-1-blocking antibody that blocks the interaction between the PD-1 receptor and its ligands, PD-L1 and PD-L2. It is an IgG4 kappa immunoglobulin blocking antibody. By blocking the PD-1 receptor pathway, the drug may block the PD-1-mediated negative regulatory $\mathrm{T}$-cell signaling in order to allow for T-cell activation to create an antitumor immune response. It is likely that the function of pembrolizumab is much more complex, involving an intricate relationship between PD-1 and other immune modulatory pathways. Notably, PD-1 acts via a distinct mechanism from CTLA-4 to inhibit T-cell activation. ${ }^{13}$

Pembrolizumab has a long elimination half-life of 26 days, with steady-state concentrations reached by 18 weeks on an every 3-week regimen with dose-proportional pharmacokinetic parameters in the dose range of $2-10 \mathrm{mg} / \mathrm{kg}$ every 3 weeks. No clinically important differences in pembrolizumab clearance were noted between patients with renal impairment and patients with normal renal function, nor were there differences in clearance between patients with mild hepatic dysfunction and normal function. ${ }^{14}$

\section{Efficacy, safety, and tolerability of pembrolizumab \\ Melanoma}

Patients with advanced melanoma were initially enrolled in a Phase I clinical trial of pembrolizumab for patients with advanced solid tumors (KEYNOTE-001, NCT01295827) in late 2011. When initial efficacy data were first reported in abstract form in 2012 in patients with melanoma, the study protocol had been amended to add additional cohorts of melanoma patients. ${ }^{15}$ Accrual proceeded rapidly; 135 patients with advanced melanoma who either had or had not previously been treated with ipilimumab were treated in sequential nonrandomized cohorts with pembrolizumab at doses of $10 \mathrm{mg} / \mathrm{kg}$ every 2 weeks, $10 \mathrm{mg} / \mathrm{kg}$ every 3 weeks, and $2 \mathrm{mg} / \mathrm{kg}$ every 3 weeks. Also, 276 additional patients were subsequently enrolled in two randomized cohorts, and 173 of these patients had disease defined as ipilimumab refractory and the remaining 103 patients were ipilimumab naïve. Within each subset, patients were randomized to receive pembrolizumab at a dose of either 10 or $2 \mathrm{mg} / \mathrm{kg}$ every 3 weeks.

Data from the first 135 patients enrolled in KEYNOTE001 were published in 2013 , with a centrally confirmed RECIST objective response rate of $38 \%$ and no difference in the response rates of those patients who had and had not received prior ipilimumab. Responses were very durable, with 42 of the 52 responding patients (81\%) still receiving treatment at the time of analysis. ${ }^{16}$

Data from the 173 ipilimumab-refractory patients enrolled in the randomized cohorts of KEYNOTE-001 were published in 2014, with no difference in response rates for patients randomized to receive pembrolizumab $2 \mathrm{mg} / \mathrm{kg}$ every 3 weeks or $10 \mathrm{mg} / \mathrm{kg}$ every 3 weeks. ${ }^{17}$ The centrally confirmed objective response rate was $26 \%$ in both the dose cohorts of ipilimumab-refractory patients. The lack of dose dependence of response rate was also confirmed in ipilimumab treatmentnaïve patients. The centrally confirmed response rates for the 103 ipilimumab-naïve patients randomized to receive pembrolizumab at doses of either $2 \mathrm{mg} / \mathrm{kg}$ every 3 weeks or $10 \mathrm{mg} / \mathrm{kg}$ every 3 weeks were $33 \%$ and $40 \%$, respectively $(P=0.4835)$, which were not statistically different. ${ }^{18}$

Overall, the objective response rate from all 411 patients with advanced melanoma enrolled in all cohorts of KEYNOTE-001 was 34\%, with some amount of tumor shrinkage in $72 \%$ of patients. Responses were observed in patients with ECOG performance status 0 or 1, LDH level elevated or normal, and with or without brain metastases. Responses were observed in all subsets of patients, 


\section{A}

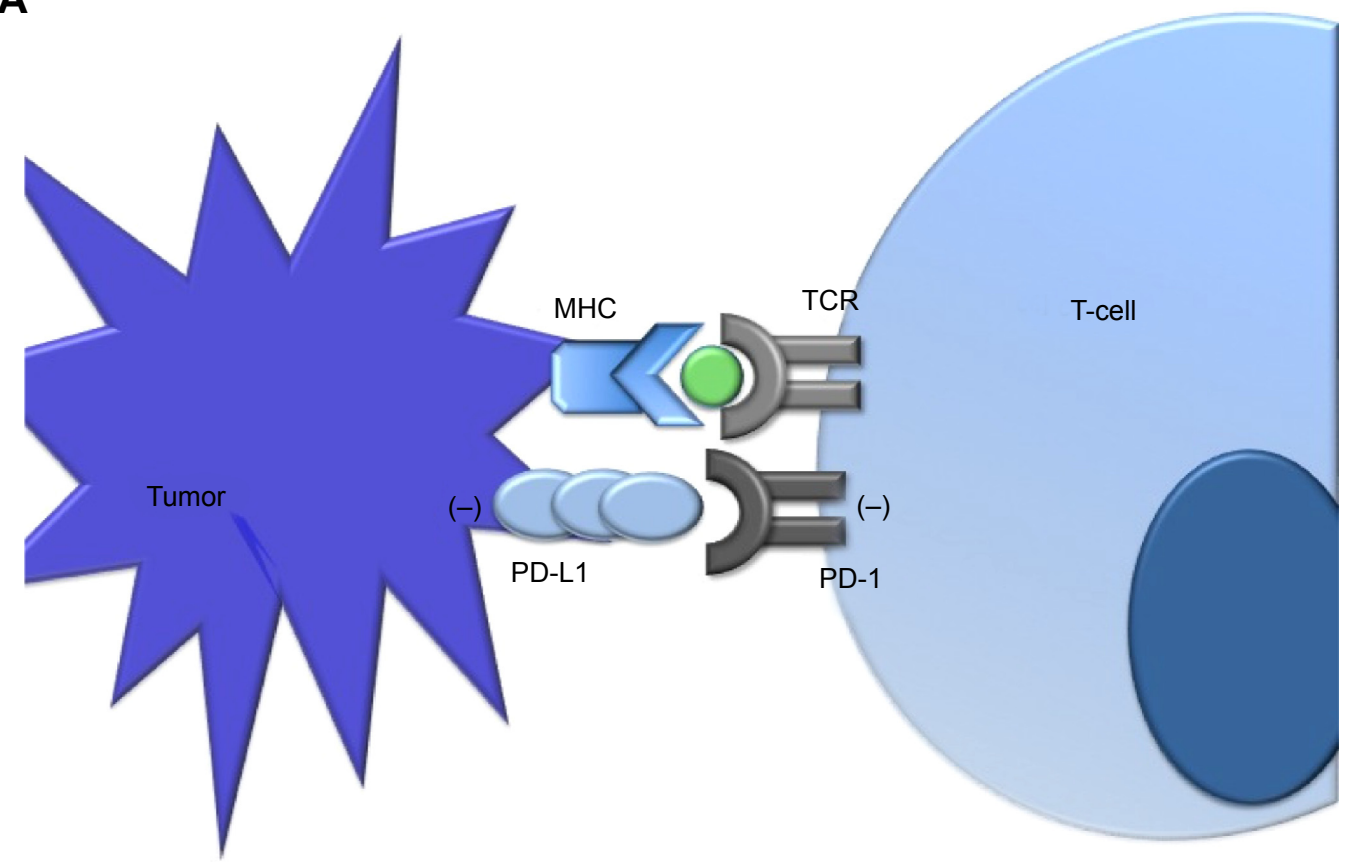

B

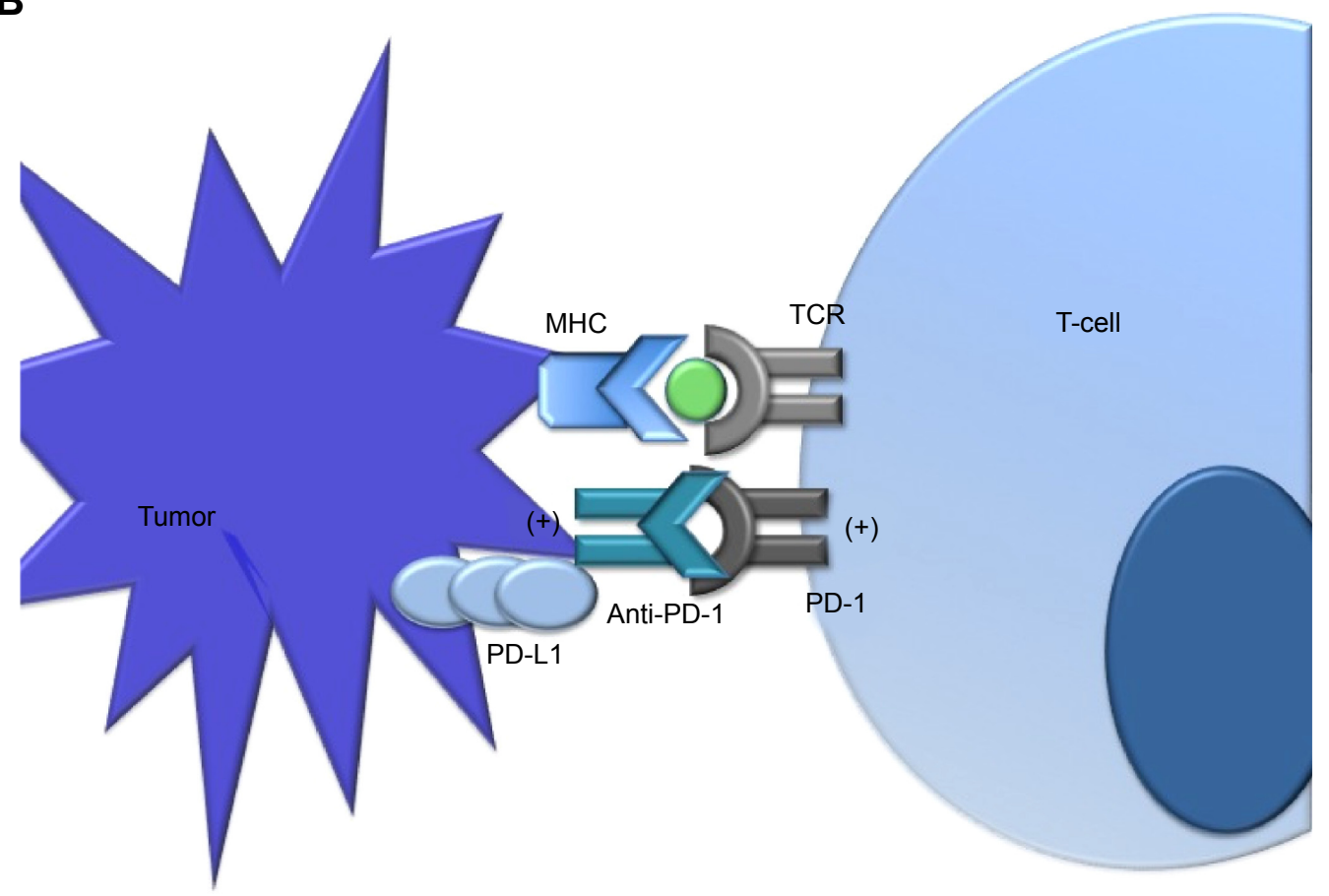

Figure I Overview of the PD-I pathway.

Notes: (A) Binding of PD-I on the T cell with tumor-associated PD-LI results in downregulation of T-cell effector functions. (B) Blocking this interaction with an anti-PD-I antibody prevents this downregulation and restores potential antitumor activity.

Abbreviations: MHC, major histocompatibility complex; TCR, T-cell receptor; PD-I, programmed death I; PD-LI, PD-I ligand.

regardless of their $\mathrm{M}$ stage, BRAF mutation status, prior BRAF/MEK inhibitor treatment, prior ipilimumab, or prior chemotherapy. ${ }^{19}$ There was evidence that patients with a smaller baseline tumor size had a significantly higher response rate and survival compared to patients with a larger baseline tumor size, as defined by the sum of the long dimension of RECIST target lesions at baseline. Baseline tumor size was the only factor predictive of response and prognostic of survival in a multivariate analysis including $\mathrm{M}$ stage and prior treatment, among other factors. ${ }^{20}$ 
Patients with increased PD-L1 expression were more likely to have an objective response compared to patients with no PD-L1 tumor expression, with response rates of $49 \%$ and $13 \%$, respectively $(P=0.0007)$. PD-L1 positivity was defined as staining in $1 \%$ or more of tumor cells. ${ }^{19}$

Of note, overall response rates (ORRs) were slightly higher when assessed by investigator review using the immune-related response criteria ${ }^{21}$ compared to the RECIST response rates reported by the independent central radiology review (37\% vs 34\%, respectively). ${ }^{22}$ Patients with progression by RECIST but nonprogression by immunerelated response criteria had an improved overall survival compared to patients with progressive disease by both criteria. In general, patients with mild asymptomatic radiographic progression and without any unacceptable toxicity can continue treatment with pembrolizumab until repeat radiographic confirmation of progressive disease; in some cases, either a delayed response or a response after initial mild progression or the appearance of new lesions can be observed.

More recently, pembrolizumab has been compared to cytotoxic chemotherapy in a randomized trial (KEYNOTE002, NCT01704287) in patients with advanced melanoma who had previously been treated with ipilimumab and also a BRAF or MEK inhibitor if BRAF-mutant melanoma. Objective responses were observed in $21 \%$ and $25 \%$ of patients treated with pembrolizumab 2 and $10 \mathrm{mg} / \mathrm{kg}$ every 3 weeks, respectively. There was no statistical difference in the response rates for the two doses; both response rates were higher than that for chemotherapy (4\%) as expected $(P<0.0001)$, with durable ongoing responses in almost all patients. ${ }^{23}$ Pembrolizumab resulted in significantly smaller changes from baseline compared to chemotherapy in a study of health-related quality of life in KEYNOTE-002 patients, using the global health status/quality-of-life scale of the EORTC QLQ-C30 ( $P=0.01)$.

Pembrolizumab is generally well tolerated, with serious treatment-related adverse events being rare. There were no treatment-related deaths in the 411 patients with advanced melanoma enrolled in KEYNOTE-001 or in the 540 patients enrolled in KEYNOTE-002. Treatment-related adverse events led to discontinuation in $4 \%$ of patients in KEYNOTE001 , with $12 \%$ of patients experiencing grade 3-4 treatmentrelated adverse events. No specific grade 3 or 4 adverse event occurred in more than $2 \%$ of patients, with $2 \%$ of patients experiencing grade 3 or 4 fatigue and less than $1 \%$ of patients experiencing grade 3 or 4 pruritus, rash, diarrhea, nausea, headache, hypothyroidism, decreased appetite, dyspnea, and increased ALT. About 8\% of patients did experience hypothyroidism of any grade.

Pembrolizumab gained regulatory approval by the US Food and Drug Association (FDA) in 2014 for the treatment of patients with unresectable stage III or stage IV melanoma with disease progression after ipilimumab and, if BRAF V600-mutant melanoma, a BRAF inhibitor. A randomized Phase III trial of pembrolizumab compared to ipilimumab in previously untreated patients with advanced melanoma has completed accrual (KEYNOTE-006, NCT01866319). Additional trials of pembrolizumab in melanoma are focused on combination therapy approaches with other immune therapies or targeted therapy.

In addition to the data seen with pembrolizumab, nivolumab, the fully human IgG4 antibody targeted against PD-1, has also demonstrated clinical activity in melanoma. An updated analysis of 107 melanoma patients treated with nivolumab demonstrated an ORR of $31 \%$, with a median response duration of 2 years. ${ }^{24}$ Additionally, the combination of nivolumab with other checkpoint inhibitors, including the CTLA-4 antibody, ipilimumab, has also demonstrated promise. In results reported from a Phase I dose escalation study, ORRs appear to be higher with the combination, albeit with some increase in toxicity. ${ }^{25}$

\section{Pembrolizumab in other tumor types}

While clinical data to support the efficacy of pembrolizumab have been clearly demonstrated in advanced melanoma, evidence of clinical activity has also been seen in other tumor types, highlighting the potential for the broad application of immuno-oncology across multiple diseases, even those previously not thought to be responsive to immunologic approaches (Table 1).

\section{Non-small cell lung cancer}

Traditionally, the mainstay of treatment for advanced nonsmall cell lung cancer (NSCLC) has been with platinumbased chemotherapy, though an increased understanding of the molecular pathogenesis of the disease has led to multiple novel targets for specific patient subsets in recent years. ${ }^{26-30}$ However, despite the potential for marked responses, for the majority of patients with advanced disease, durable responses remain rare. Historically, immunotherapeutic approaches with vaccines, IL-2, and interferon had shown limited or no benefit in the NSCLC population, and had substantial toxicity. ${ }^{31,32}$ However, early signals of clinical activity with immune checkpoint blockade were seen in NSCLC patient cohorts with the anti-CTLA-4 antibody 
Table I Selected PD-I-based trials in advanced solid tumors

\begin{tabular}{|c|c|c|c|c|c|c|c|}
\hline Study & Agent & Patient population & Trial design & Pts & $\begin{array}{l}\mathbf{R R} \\
\text { (\%) }\end{array}$ & $\begin{array}{l}\text { Median } \\
\text { OS (month) }\end{array}$ & $\begin{array}{l}\text { I year } \\
\text { OS (\%) }\end{array}$ \\
\hline \multicolumn{8}{|l|}{ Melanoma } \\
\hline Topalian et $\mathrm{al}^{24}$ & Nivolumab & Previously treated & Phase I, dose escalation/expansion & 107 & 31 & 16.8 & 62 \\
\hline Hamid et $\mathrm{al}^{16}$ & Pembrolizumab & $\begin{array}{l}\text { Multiple cohorts; ipilimumab } \\
\text { refractory and naïve }\end{array}$ & Phase I, dose escalation/expansion & 135 & 38 & NR & NR \\
\hline \multirow[t]{3}{*}{ Robert et al ${ }^{17}$} & Pembrolizumab & Ipilimumab refractory & Randomized dose comparison cohort & & & & \\
\hline & & & $2 \mathrm{mg} / \mathrm{kg}$ vs & 81 & 26 & NR & 58 \\
\hline & & & $10 \mathrm{mg} / \mathrm{kg}$ & 76 & 26 & & 63 \\
\hline \multirow[t]{4}{*}{ Ribas et $\mathrm{al}^{23}$} & Pembrolizumab & Ipilimumab refractory & Phase II randomized, two dose cohorts & & & NR & NR \\
\hline & & & $(2 \mathrm{mg} / \mathrm{kg}$ and & 180 & 21 & & \\
\hline & & & $10 \mathrm{mg} / \mathrm{kg})$ & $|8|$ & 25 & & \\
\hline & & & vs chemotherapy with crossover & 179 & 4 & & \\
\hline \multirow[t]{3}{*}{ Robert et al ${ }^{67}$} & Nivolumab & No prior treatment & Randomized, blinded dacarbazine & 208 & 13.9 & 10.8 & 42 \\
\hline & & BRAF wild type & vs & & & & \\
\hline & & & nivolumab & 210 & 40 & Not reached & 72.9 \\
\hline \multicolumn{8}{|l|}{ NSCLC } \\
\hline Brahmer et $\mathrm{al}^{43}$ & Nivolumab & Previously treated & Phase I, dose escalation/expansion & 129 & 17 & 9.6 & 42 \\
\hline Garon et al ${ }^{44}$ & Pembrolizumab & Previously treated & Randomized at two dosing schedules & 305 & $23^{\mathrm{a}}$ & NR & NR \\
\hline \multirow[t]{2}{*}{ Rizvi et al ${ }^{45}$} & Pembrolizumab & No prior treatment & three dosing schedules & 45 & 26 & NR & NR \\
\hline & & PD-LI+ patients & & & & & \\
\hline \multicolumn{8}{|l|}{$\mathrm{RCC}$} \\
\hline Topalian et $\mathrm{a}^{35}$ & Nivolumab & Previously treated & $\begin{array}{l}\text { Expansion cohort of Phase I } \\
\text { trial; two doses }\end{array}$ & 33 & 27 & NR & NR \\
\hline \multicolumn{8}{|l|}{ HNSCC } \\
\hline Seiwert et $\mathrm{a}^{59}$ & Pembrolizumab & Previously treated & Phase lb expansion study & 60 & 20 & NR & NR \\
\hline & & PD-LI+ patients & & & & & \\
\hline
\end{tabular}

Note: aPD-LI+ patients.

Abbreviations: Pts, patients; RR, relative risk; OS, overall survival; NR, not reported; NSCLC, non-small cell lung cancer; RCC, renal cell carcinoma; HNSCC, head and neck squamous cell carcinoma; PD-I, programmed death I; PD-LI, PD-I ligand.

ipilimumab as well as with PD-1- and PD-L1-based approaches, suggesting that lung cancers could respond to immunotherapy. ${ }^{33-35}$

PD-L1 expression has been studied in a number of resected NSCLC specimens, and has been seen in approximately $25 \%-50 \%$ of cases, underscoring a potential role for PD-1-based therapy. ${ }^{36-39}$ In rarer subsets, such as sarcomatoid NSCLC, more than two thirds of tumors express PD-L1. ${ }^{40}$ However, the definitive prognostic significance of PD-L1 expression is yet to be determined, with mixed results across reported studies. ${ }^{37,38,41,42}$

Nivolumab was one of the first PD-1 inhibitors to demonstrate promising results in NSCLC. ${ }^{43}$ In a cohort of 129 NSCLC patients treated on a Phase I trial, the ORR was $17 \%$, and the median duration of response was 74 weeks. Consistent with prior response patterns to immunotherapy, a subset of patients appeared to derive long-term benefits, with a 1 -year survival rate of $42 \%$ and a 2 -year rate of $24 \%$. These results were especially promising in light of the fact that these patients were heavily pretreated, with more than half having received at least three lines of therapy. ${ }^{43}$
Results of an early-phase trial of pembrolizumab also demonstrate comparable clinical activity in previously treated patients with NSCLC. ${ }^{44}$ In this study, patients were randomized to receive pembrolizumab at $10 \mathrm{mg} / \mathrm{kg}$ given either every 2 or 3 weeks. A total of 305 patients were eligible based on any detectable level of PD-L1 expression out of 450 patients screened, though some patients whose tumors were negative for PD-L1 were treated in the every 2-week cohort. The (confirmed and unconfirmed) ORR by RECIST 1.1 for patients whose tumors expressed PD-L1 was $26 \%$ $(\mathrm{CI}=15-40)$ in the 2 -week cohort and $21 \%(\mathrm{CI}=13-30)$ in the 3-week cohort. The majority of responses appeared to be durable. Some responses were still seen in patients whose tumors did not express PD-L1, albeit at lower rates $(9 \%$, $\mathrm{CI}=2-23$ ). Drug-related toxicities were manageable and consistent with agents in this class, the most common being fatigue, decreased appetite, arthralgia, pruritus, and rash. Of note, four cases of drug-related grade 3/4 pneumonitis were seen. Additional patients are currently being enrolled to this study, as well as to a combination study of pembrolizumab with docetaxel for patients with NSCLC who have received at 
least one prior therapy (NCT01905657). In the first-line setting, pembrolizumab has also shown promising clinical activity in early-phase studies. ${ }^{45}$ In a recent trial, pembrolizumab was administered at three different dosing schedules $(2 \mathrm{mg} / \mathrm{kg}$ every 3 weeks, $10 \mathrm{mg} / \mathrm{kg}$ every 3 weeks, $10 \mathrm{mg} / \mathrm{kg}$ every 2 weeks) to 57 patients with advanced NSCLC whose tumors expressed PD-L1 by immunohistochemistry (IHC). Patients had not received any prior therapy for advanced NSCLC, though chemotherapy in the adjuvant setting was allowed if more than 1 year had elapsed. Eighty-four patients were screened, and 57 had tumors that expressed PD-L1; 45 met all eligibility criteria and subsequently enrolled in the study. The best ORR by RECIST for the total population was $26 \%$ (14-42). The response rate was 33\% (4-78) in the $2 \mathrm{mg} / \mathrm{kg}$ cohort and $20 \%(6-44)$ and $31 \%(11-59)$ in the $10 \mathrm{mg} / \mathrm{kg}$ arms (every 3 weeks/every 2 weeks), respectively. Preliminary progression-free survival was 27 weeks, with $56 \%$ of patients remaining on treatment at the time of the analysis. Overall, toxicities compared favorably with other regimens and included fatigue, pruritus, diarrhea, and dyspnea. The only grade 3 adverse events were a pericardial effusion and pneumonitis. Larger, randomized studies in the first-line setting are planned or are currently underway.

\section{Genitourinary cancers}

Immunotherapeutic approaches have also been shown to be a viable option for subsets of patients with RCC, historically with high-dose IL-2 or interferon- $\alpha 2 \mathrm{~B} .{ }^{46,47} \mathrm{As}$ in melanoma, high-dose IL-2 was approved for the ability to induce durable complete responses (CRs) in a small proportion of patients; however, the treatment is associated with substantial toxicity. Interferon- $\alpha 2 \mathrm{~B}$ is currently considered as a first-line option in combination with bevacizumab for selected patients with clear cell histology. ${ }^{48}$ Advances have identified other strategies that have improved outcomes, including antiangiogenic-based therapies as well as targeting mammalian target of rapamycin, though CRs with targeted agents are rare. ${ }^{49}$

Most recently, the potential for PD-1-based therapies has reignited the interest in immunotherapeutic approaches for this disease. Preclinical data suggest that targeting the PD-1 pathway may show promise in RCC as well. In a large retrospective series of nephrectomy specimens, PD-1 was interestingly shown to be expressed by surrounding immune cells, and was present in approximately half of tumors with mononuclear infiltrates. ${ }^{50}$ In this study, the presence of PD-1positive cells was associated with more adverse prognostic features and a worse overall survival, suggesting a role for therapies directed against PD-1. Early clinical activity has also been seen with PD-1-based approaches for RCC. In an expansion cohort of 33 RCC patients treated on a Phase I study with nivolumab, objective responses were seen in $24 \%$ of patients treated with $1 \mathrm{mg} / \mathrm{kg}$ and in $31 \%$ of patients treated with $10 \mathrm{mg} / \mathrm{kg}$; additionally, it appeared that many of these responses were durable. ${ }^{35}$ Additionally, preclinical observations have suggested that antiangiogenic therapies may affect the tumor microenvironment and allow for synergy with immunotherapies. ${ }^{51,52}$ A number of combination strategies are currently underway, including a clinical trial assessing the safety of pembrolizumab in combination with the angiogenesis inhibitor pazopanib (NCT02014636).

In prostate cancer, analyses of prostatectomy specimens have shown that intra- and peritumoral lymphocytes express PD-1, suggesting that manipulation of this pathway could be of potential clinical interest. ${ }^{53,54}$ However, to date, there has been limited efficacy seen with PD-1-targeted therapy in castrate-resistant prostate cancer (CRPC), despite some early promise seen with other immunomodulatory agents such as ipilimumab, though limited data exist at this point. ${ }^{55}$ In the Phase I trial of nivolumab, 17 patients with metastatic CRPC were treated, and no responses were seen; in the two patients whose tumors were tested, PD-L1 was not expressed, which may be an important predictor of response. ${ }^{35}$

\section{Head and neck squamous cell carcinoma}

Head and neck squamous cell carcinoma is potentially curable in many patients, but recurrent or metastatic disease is difficult to treat, and once diagnosed, median survival is just over 1 year. ${ }^{56,57}$ Current therapeutic options are limited, and include standard cytotoxic chemotherapies or the EGFR-targeted antibody cetuximab. ${ }^{58}$ In a recent study of patients with recurrent or metastatic head and neck cancer, pembrolizumab demonstrated early signals of promising clinical activity. ${ }^{59}$ In this Phase Ib expansion study, patients whose tumors expressed PD-L1 (defined as $>1 \%$ positive cells in stroma or on tumor cells by IHC) were treated with pembrolizumab at $10 \mathrm{mg} / \mathrm{kg}$ every 2 weeks. HPV-positive and HPV-negative patients were treated in separate cohorts. Nearly $80 \%$ of patients screened were positive for PD-L1 expression, and 60 patients were treated. Most patients had received at least one prior line of therapy. Overall, pembrolizumab appeared to be well tolerated, and the most common side effects were fatigue and pruritus. There were very few severe adverse events, the most common being rash. Approximately half of patients had a decrease in tumor size, with $20 \%$ of patients having a response by RECIST criteria; 
the majority of responses appeared to be ongoing. Interestingly, both HPV-positive and HPV-negative patients had similar response rates. In an exploratory analysis, the degree of PD-L1 expression appeared to correlate with response. An additional expansion of this study is currently underway, and Phase III studies in this patient population are planned.

\section{Colorectal cancer}

Analyses of tumor specimens have shown that a number of gastrointestinal malignancies express PD-L1, including approximately $50 \%$ of colorectal cancers (CRCs).$^{60}$ More recent analyses have looked at the association of PD-L1 expression in the context of the molecular genetics of CRC, as the role of PD-L1 continues to be defined. In a study of 77 clinically annotated CRC specimens, $47 \%$ of sporadic CRC cases had PD-1-positive intraepithelial lymphocytes. ${ }^{61}$ When analyzing this by microsatellite instability (MSI), it was found that MSI-high (MSI-H) tumors had a significantly higher expression of PD-1-positive lymphocytes when compared to MSI-low (MSI-L) tumors ( $72 \%$ vs 39\%, $P<0.03)$. Additionally, MSI-H tumors appeared to have a higher rate of expression of PD-L1 when compared to MSI-L tumors (56\% vs $21 \%, P=0.007$ ). Other studies, however, have shown mismatch repair-deficient $\mathrm{CRC}$ to have a lower rate of PD-L1 positivity. ${ }^{62}$

Clinically, there has been early evidence of activity of PD-1-based therapy in CRC. In a Phase I study of nivolumab that included 39 patients, one patient with metastatic CRC had a durable CR. ${ }^{63}$ Interestingly, a pretreatment tumor specimen revealed membranous expression of PD-L1 on tumor-infiltrating macrophages and lymphocytes and on rare tumor cells, as well as PD-1-positive $\mathrm{CD}^{+} \mathrm{T}$ cells. ${ }^{64}$ Studies are currently underway with nivolumab as well as pembrolizumab in this patient population. Given the potential differences in susceptibility to modulation with immune checkpoint inhibitors in MSI-H versus MSI-L tumors, a Phase II study of pembrolizumab in patients with CRC is currently enrolling patients (NCT01876511). In this study, patients with MSI-H and MSI-L metastatic CRC will receive pembrolizumab monotherapy in separate cohorts.

\section{Hematologic malignancies}

A number of other cancers have been shown to express PD-L1, suggesting that immune checkpoint blockade could be beneficial in these malignancies as well ${ }^{65}$ In hematologic malignancies, the PD-1 antibody CT-011 has shown evidence of clinical activity. Of 17 patients, one patient with nonHodgkin's lymphoma had a CR. ${ }^{66}$ Trials of pembrolizumab in this setting are planned or are currently underway, including studies of pembrolizumab monotherapy as well as a combination study with lenalidomide and low-dose dexamethasone in patients with refractory multiple myeloma.

\section{Conclusion}

The successful development of PD-1-based therapy represents a breakthrough in the field of immuno-oncology that has the potential to impact treatment options for many different cancers. Pembrolizumab has demonstrated promising clinical activity in melanoma, and was recently FDA approved for patients whose disease has progressed on ipilimumab and a BRAF inhibitor if indicated. Regarding melanoma, first-line trials are currently underway or have recently been completed. In other malignancies, including NSCLC and RCC, PD-1targeted agents, including pembrolizumab and nivolumab, have shown clear evidence of antitumor activity. The unique side effect profile of PD-1-directed therapy makes it a particularly attractive therapeutic strategy for many malignancies, where current standards are often associated with substantial toxicities. Overall, agents in this class, including pembrolizumab, appear to be very well tolerated, and relatively few serious adverse events have been noted. In the future, it is likely that combination strategies will play a key role, and will need to be tailored to specific malignancies. Additionally, continuous exploration of predictive and prognostic markers, as well as a better understanding of mechanisms of resistance, will allow for improved outcomes for many patients.

\section{Disclosure}

Dr Salama receives research funding from Bristol-Myers Squibb, and has served as a consultant for Roche-Genentech. Dr Gangadhar has received honoraria from Merck. The authors report no other conflicts of interest in this work.

\section{References}

1. Rosenberg SA, Yang JC, Topalian SL, et al. Treatment of 283 consecutive patients with metastatic melanoma or renal cell cancer using high-dose bolus interleukin 2. JAMA. 1994;271(12):907-913.

2. Kirkwood JM, Strawderman MH, Ernstoff MS, Smith TJ, Borden EC, Blum RH. Interferon alfa-2b adjuvant therapy of high-risk resected cutaneous melanoma: the Eastern Cooperative Oncology Group Trial EST 1684. J Clin Oncol. 1996;14(1):7-17.

3. Hodi FS, O'Day SJ, McDermott DF, et al. Improved survival with ipilimumab in patients with metastatic melanoma. $N$ Engl J Med. 2010;363(8):711-723.

4. Kantoff PW, Higano CS, Shore ND, et al. Sipuleucel-T immunotherapy for castration-resistant prostate cancer. $N$ Engl J Med. 2010;363(5): $411-422$.

5. Zajac AJ, Blattman JN, Murali-Krishna K, et al. Viral immune evasion due to persistence of activated T cells without effector function. $J$ Exp Med. 1998;188(12):2205-2213.

6. Wherry EJ. T cell exhaustion. Nat Immunol. 2011;12(6):492-499. 
7. Virgin HW, Wherry EJ, Ahmed R. Redefining chronic viral infection. Cell. 2009;138(1):30-50.

8. Barber DL, Wherry EJ, Masopust D, et al. Restoring function in exhausted CD8 T cells during chronic viral infection. Nature. 2006; 439(7077):682-687.

9. Trautmann L, Janbazian L, Chomont N, et al. Upregulation of PD-1 expression on HIV-specific $\mathrm{CD} 8^{+} \mathrm{T}$ cells leads to reversible immune dysfunction. Nat Med. 2006;12(10):1198-1202.

10. Francisco LM, Salinas VH, Brown KE, et al. PD-L1 regulates the development, maintenance, and function of induced regulatory T cells. J Exp Med. 2009;206(13):3015-3029.

11. Day CL, Kaufmann DE, Kiepiela P, et al. PD-1 expression on HIVspecific $\mathrm{T}$ cells is associated with T-cell exhaustion and disease progression. Nature. 2006;443(7109):350-354.

12. Petrovas C, Casazza JP, Brenchley JM, et al. PD-1 is a regulator of virus-specific $\mathrm{CD}^{+} \mathrm{T}$ cell survival in HIV infection. J Exp Med. 2006; 203(10):2281-2292.

13. Parry RV, Chemnitz JM, Frauwirth KA, et al. CTLA-4 and PD-1 receptors inhibit T-cell activation by distinct mechanisms. Mol Cell Biol. 2005;25(21):9543-9553.

14. KEYTRUDA ${ }^{\circledR}$ (pembrolizumab) [package insert]. Whitehouse Station, NJ: Merck; 2014. Accessed November 26, 2014.

15. Hamid O. Efficacy and safety of MK-3475 in patients with advanced melanoma. Presented at: The Society for Melanoma Research 2012 Congress, Hollywood, CA, November 8-11, 2012.

16. Hamid O, Robert C, Daud A, et al. Safety and tumor responses with lambrolizumab (anti-PD-1) in melanoma. $N$ Engl J Med. 2013; 369(2):134-144.

17. Robert C, Ribas A, Wolchok JD, et al. Anti-programmed-death-receptor-1 treatment with pembrolizumab in ipilimumab-refractory advanced melanoma: a randomised dose-comparison cohort of a phase 1 trial. Lancet. 2014;384(9948):1109-1117.

18. Hamid O, Robert C, Ribas A, et al. Randomized comparison of two doses of the anti-PD-1 monoclonal antibody MK-3475 for ipilimumabrefractory (IPI-R) and IPI-naive (IPI-N) melanoma (MEL) [abstr 3000]. J Clin Oncol. 2014;32(Suppl):5S.

19. Ribas A, Hodi FS, Kefford R, et al. Efficacy and safety of the anti-PD-1 monoclonal antibody MK-3475 in 411 patients (pts) with melanoma (MEL) [abstr LBA9000]. J Clin Oncol. 2014;32(Suppl):5S

20. Joseph RW, Elassaiss-Schaap J, Wolchok J, et al. Baseline tumor size as an independent prognostic factor for overall survival in patients with metastatic melanoma treated with the anti-PD-1 monoclonal antibody MK-3475 [abstr 3015]. J Clin Oncol. 2014;32(Suppl):5S.

21. Wolchok JD, Hoos A, O'Day S, et al. Guidelines for the evaluation of immune therapy activity in solid tumors: immune-related response criteria. Clin Cancer Res. 2009;15(23):7412-7420.

22. Hodi FS, Ribas A, Daud A, et al. Evaluation of immune-related response criteria (irRC) in patients (pts) with advanced melanoma (MEL) treated with the anti-PD-1 monoclonal antibody MK-3475 [abstr 3006]. J Clin Oncol. 2014;32(Suppl):5S.

23. Ribas A, Puzanov I, Dummer R, et al. A randomized controlled comparison of pembrolizumab and chemotherapy in patients with ipilimumab-refractory melanoma. Presented at: Society for Melanoma Research 2014 International Congress, Zurich, Switzerland, 13-16 November, 2014.

24. Topalian SL, Sznol M, McDermott DF, et al. Survival, durable tumor remission, and long-term safety in patients with advanced melanoma receiving nivolumab. J Clin Oncol. 2014;32(10):1020-1030.

25. Wolchok JD, Kluger H, Callahan MK, et al. Nivolumab plus ipilimumab in advanced melanoma. $N$ Engl J Med. 2013;369(2):122-133.

26. Douillard JY, Shepherd FA, Hirsh V, et al. Molecular predictors of outcome with gefitinib and docetaxel in previously treated non-smallcell lung cancer: data from the randomized phase III INTEREST trial. J Clin Oncol. 2010;28(5):744-752.

27. Kwak EL, Bang YJ, Camidge DR, et al. Anaplastic lymphoma kinase inhibition in non-small-cell lung cancer. N Engl J Med. 2010;363(18): 1693-1703.
28. Mok TS, Wu YL, Thongprasert S, et al. Gefitinib or carboplatinpaclitaxel in pulmonary adenocarcinoma. $N$ Engl J Med. 2009;361 (10):947-957.

29. Shaw AT, Ou SH, Bang YJ, et al. Crizotinib in ROS1-rearranged nonsmall-cell lung cancer. $N$ Engl J Med. 2014;371(21):1963-1971.

30. Zhou C, Wu YL, Chen G, et al. Erlotinib versus chemotherapy as first-line treatment for patients with advanced EGFR mutation-positive non-small-cell lung cancer (OPTIMAL, CTONG-0802): a multicentre, open-label, randomised, phase 3 study. Lancet Oncol. 2011; 12(8):735-742.

31. Al-Moundhri M, O'Brien M, Souberbielle BE. Immunotherapy in lung cancer. Br J Cancer. 1998;78(3):282-288.

32. Salgaller ML. The development of immunotherapies for non-small cell lung cancer. Expert Opin Biol Ther. 2002;2(3):265-278.

33. Lynch TJ, Bondarenko I, Luft A, et al. Ipilimumab in combination with paclitaxel and carboplatin as first-line treatment in stage IIIB/ IV non-small-cell lung cancer: results from a randomized, doubleblind, multicenter phase II study. J Clin Oncol. 2012;30(17): 2046-2054.

34. Brahmer JR, Tykodi SS, Chow LQ, et al. Safety and activity of antiPD-L1 antibody in patients with advanced cancer. $N$ Engl J Med. 2012;366(26):2455-2465

35. Topalian SL, Hodi FS, Brahmer JR, et al. Safety, activity, and immune correlates of anti-PD-1 antibody in cancer. $N$ Engl $J$ Med. 2012;366(26):2443-2454.

36. Yang CY, Lin MW, Chang YL, Wu CT, Yang PC. Programmed cell death-ligand 1 expression in surgically resected stage I pulmonary adenocarcinoma and its correlation with driver mutations and clinical outcomes. Eur J Cancer. 2014;50(7):1361-1369.

37. Velcheti V, Schalper KA, Carvajal DE, et al. Programmed death ligand-1 expression in non-small cell lung cancer. Lab Invest. 2014; 94(1):107-116

38. Boland JM, Kwon ED, Harrington SM, et al. Tumor B7-H1 and B7-H3 expression in squamous cell carcinoma of the lung. Clin Lung Cancer. 2013;14(2):157-163.

39. Konishi J, Yamazaki K, Azuma M, Kinoshita I, Dosaka-Akita H, Nishimura M. B7-H1 expression on non-small cell lung cancer cells and its relationship with tumor-infiltrating lymphocytes and their PD-1 expression. Clin Cancer Res. 2004;10(15):5094-5100.

40. Velcheti V, Rimm DL, Schalper KA. Sarcomatoid lung carcinomas show high levels of programmed death ligand-1 (PD-L1). $J$ Thorac Oncol. 2013;8(6):803-805.

41. Chen YB, Mu CY, Huang JA. Clinical significance of programmed death-1 ligand-1 expression in patients with non-small cell lung cancer: a 5-year-follow-up study. Tumori. 2012;98(6):751-755.

42. Mu CY, Huang JA, Chen Y, Chen C, Zhang XG. High expression of PD-L1 in lung cancer may contribute to poor prognosis and tumor cells immune escape through suppressing tumor infiltrating dendritic cells maturation. Med Oncol. 2011;28(3):682-688.

43. Brahmer JR, Horn L, Antonia S, et al. Nivolumab (anti-PD-1; BMS936558; ONO-4538) in patients with non-small cell lung cancer (NSCLC): overall survival and long-term safety in a phase 1 trial. Presented at: IASLC 15th World Conference on Lung Cancer, Sydney, Australia, October 22-30, 2013.

44. Garon EB, Leighl NB, Rizvi NA, et al. Safety and clinical activity of MK-3475 in previously treated patients (pts) with non-small cell lung cancer (NSCLC). Presented at: The American Society of Clinical Oncology Annual Meeting, Chicago, IL, USA, October 22-30, 2013.

45. Rizvi NA, Garon EB, Patnaik A, et al. Safety and clinical activity of MK-3475 as initial therapy in patients with advanced non-small cell lung cancer (NSCLC). Presented at: The American Society of Clinical Oncology Annual Meeting, Chicago, IL, USA, May 30-June 3, 2014.

46. Fyfe G, Fisher RI, Rosenberg SA, Sznol M, Parkinson DR, Louie AC. Results of treatment of 255 patients with metastatic renal cell carcinoma who received high-dose recombinant interleukin-2 therapy. $J$ Clin Oncol. 1995;13(3):688-696. 
47. Fisher RI, Rosenberg SA, Fyfe G. Long-term survival update for highdose recombinant interleukin-2 in patients with renal cell carcinoma. Cancer J Sci Am. 2000;6(Suppl 1):S55-S57.

48. Escudier B, Porta C, Schmidinger M, et al. Renal cell carcinoma: ESMO Clinical Practice Guidelines for diagnosis, treatment and follow-up. Ann Oncol. 2014;25(Suppl 3):iii49-iii56.

49. Coppin C, Le L, Porzsolt F, Wilt T. Targeted therapy for advanced renal cell carcinoma. Cochrane Database Syst Rev. 2008;(2):CD006017.

50. Thompson RH, Dong H, Lohse CM, et al. PD-1 is expressed by tumorinfiltrating immune cells and is associated with poor outcome for patients with renal cell carcinoma. Clin Cancer Res. 2007;13(6):1757-1761.

51. Finke JH, Rayman PA, Ko JS, Bradley JM, Gendler SJ, Cohen PA. Modification of the tumor microenvironment as a novel target of renal cell carcinoma therapeutics. Cancer J. 2013;19(4):353-364.

52. Ko JS, Zea AH, Rini BI, et al. Sunitinib mediates reversal of myeloidderived suppressor cell accumulation in renal cell carcinoma patients. Clin Cancer Res. 2009;15(6):2148-2157.

53. Sfanos KS, Bruno TC, Maris CH, et al. Phenotypic analysis of prostateinfiltrating lymphocytes reveals TH17 and Treg skewing. Clin Cancer Res. 2008;14(11):3254-3261.

54. Ebelt K, Babaryka G, Frankenberger B, et al. Prostate cancer lesions are surrounded by FOXP3+, PD-1+ and B7-H1+ lymphocyte clusters. Eur J Cancer. 2009;45(9):1664-1672.

55. Slovin SF, Higano CS, Hamid O, et al. Ipilimumab alone or in combination with radiotherapy in metastatic castration-resistant prostate cancer: results from an open-label, multicenter phase I/II study. Ann Oncol. 2013;24(7):1813-1821.

56. Brandwein-Gensler M, Smith RV. Prognostic indicators in head and neck oncology including the new 7th edition of the AJCC staging system. Head Neck Pathol. 2010;4(1):53-61.

57. Mell LK, Dignam JJ, Salama JK, et al. Predictors of competing mortality in advanced head and neck cancer. J Clin Oncol. 2010;28(1):15-20.

58. Brockstein BE, Vokes EE. Head and neck cancer in 2010: maximizing survival and minimizing toxicity. Nat Rev Clin Oncol. 2011;8(2): $72-74$.
59. Seiwert T, Burtness B, Weiss J, et al. A phase Ib study of MK-3475 in patients with human papillomavirus (HPV)-associated and non-HPVassociated head and neck (H/N) cancer [abstr 6011]. J Clin Oncol. 2014; 32(Suppl):5S.

60. Dong H, Strome SE, Salomao DR, et al. Tumor-associated B7-H1 promotes T-cell apoptosis: a potential mechanism of immune evasion. Nat Med. 2002;8(8):793-800.

61. Gatalica Z, Snyder CL, Yeats K, Xiao N, Holterman D, Lynch HT. Programmed death 1 (PD-1) lymphocytes and ligand (PD-L1) in colorectal cancer and their relationship to microsatellite instability status [abstr 3625]. J Clin Oncol. 2014;32(Suppl):5S.

62. Droeser RA, Hirt C, Viehl CT, et al. Clinical impact of programmed cell death ligand 1 expression in colorectal cancer. Eur J Cancer. 2013;49(9):2233-2242.

63. Brahmer JR, Drake CG, Wollner I, et al. Phase I study of single-agent anti-programmed death-1 (MDX-1106) in refractory solid tumors: safety, clinical activity, pharmacodynamics, and immunologic correlates. J Clin Oncol. 2010;28(19):3167-3175.

64. Lipson EJ, Sharfman WH, Drake CG, et al. Durable cancer regression off-treatment and effective reinduction therapy with an anti-PD-1 antibody. Clin Cancer Res. 2013;19(2):462-468.

65. Sznol M, Chen L. Antagonist antibodies to PD-1 and B7-H1 (PD-L1) in the treatment of advanced human cancer-response. Clin Cancer Res. 2013;19(19):5542.

66. Berger R, Rotem-Yehudar R, Slama G, et al. Phase I safety and pharmacokinetic study of CT-011, a humanized antibody interacting with PD-1, in patients with advanced hematologic malignancies. Clin Cancer Res. 2008;14(10):3044-3051.

67. Robert C, Long GV, Brady B, et al. Nivolumab in previously untreated melanoma without BRAF mutation. $N$ Engl J Med. 2015;372(4): $320-330$.
OncoTargets and Therapy

\section{Publish your work in this journal}

OncoTargets and Therapy is an international, peer-reviewed, open access journal focusing on the pathological basis of all cancers, potential targets for therapy and treatment protocols employed to improve the management of cancer patients. The journal also focuses on the impact of management programs and new therapeutic agents and protocols on

\section{Dovepress}

patient perspectives such as quality of life, adherence and satisfaction. The manuscript management system is completely online and includes a very quick and fair peer-review system, which is all easy to use. Visit http://www.dovepress.com/testimonials.php to read real quotes from published authors. 